\title{
HOME INFORMATION SYSTEMS
}

\author{
The storage problem
}

\author{
Andy Sloane, Arthur Harris and Wenyu Huang \\ CoNTACT research group, School of Computing and Information Technology, University of \\ Wolverhampton, Wolverhampton, U.K
}

Key words: Home information systems, Multimedia, Information, Storage systems

\begin{abstract}
Most service providers concentrate on delivery and this involves communication and value-added services. These are increasingly being taken up by users and new digital services are set to become ubiquitous. However, traditionally the home has been using information in a variety of ways and it is envisaged that this type of use will continue and expand, especially since the new services also have their own requirement for storage (at least in the short term). The storage of information in home has, until now, been done via a diverse range of devices and formats and physical and logical storage systems have become widespread. (e.g. books and bookcases, video cassettes, audio CDs etc.). Now storage is set to become fully digital and transitional arrangements are showing that this is not always an easy process. The ways in which users organise their stored information has largely depended on the format that was used to store it. This imposes physical restrictions on both the storage and retrieval of information in the home. One of the main considerations being ease of use and ease of location. Digital storage, whist providing a simple, robust, physically small and highly searchable store has the problems of needing specialised programmes to recreate what users may want from the systems and at the same time users may not be aware of the power of systems that are available for home use. It is our contention that both the usability, the organisation of storage, and the user's programme to access it will have far-reaching effects on the use and applicability of near-future home information systems.
\end{abstract}




\section{INTRODUCTION}

The current move to digital forms of information on terrestrial television, satellite systems and via the Internet leads to some interesting questions of what users in homes will want to do with information when it is received. The change from analogue to digital systems has taken place quite rapidly with, for example the UK government declaring [5] that analogue television transmission would be ended in 2006 , by when digital formats would be the only means of terrestrial television broadcasting. Another move, the growth of Internet support for data sources, such as newspapers and television programmes indicates a widening of the sources of information and more diversity in the type and format of information that will be used in homes.

This paper analyses the breadth of information that is available, the changes that are occurring to the format of information in the move to digital sources and the possibilities and problems involved in the storage of information in the home. Unlike the Internet broadcast problem [3] where infrastructures need to be in place before users can access the material effectively, the storage problem will need to be solved by the users themselves as the ease of use and storage capabilities will be related to the equipment used rather than outside forces.

\section{HOME INFORMATION}

At present many forms of information are used in the home from simple hand-written notes, through printed sheets to full audio-video information in the form of television broadcasts. There are many ways in which information is used by and transferred between occupants. Table 1[1] summarises the range of information used in the home and outlines the movement of information and the actors involved in its use. The following sections outline basic categories of information flow.

Table 1. Information use in the home

\begin{tabular}{|c|c|c|c|}
\hline Media & Forms & $\begin{array}{l}\text { Directions relative } \\
\text { to the home }\end{array}$ & Producers - receivers \\
\hline Post & $\begin{array}{l}\text { Text, } \\
\text { Drawing }\end{array}$ & $\begin{array}{l}\text { Incoming, } \\
\text { outgoing. }\end{array}$ & $\begin{array}{l}\text { Business } \Leftrightarrow \text { Family, } \\
\text { Family } \Leftrightarrow \text { Family }\end{array}$ \\
\hline $\begin{array}{l}\text { Printing } \\
\text { press }\end{array}$ & $\begin{array}{l}\text { Text, } \\
\text { Picture } \\
\text { drawing }\end{array}$ & Incoming. & Publishers $\rightarrow$ Family \\
\hline
\end{tabular}




\begin{tabular}{|c|c|c|c|}
\hline Media & Forms & $\begin{array}{l}\text { Directions relative } \\
\text { to the home }\end{array}$ & Producers - receivers \\
\hline $\begin{array}{l}\text { Television \& } \\
\text { Teletext }\end{array}$ & $\begin{array}{l}\text { Video, } \\
\text { Audio, } \\
\text { Text }\end{array}$ & Incoming. & Broadcasters $\rightarrow$ Family \\
\hline Cassette & Audio & $\begin{array}{l}\text { Incoming, } \\
\text { outgoing. }\end{array}$ & $\begin{array}{l}\text { Industry } \rightarrow \text { Family, } \\
\text { Between family members }\end{array}$ \\
\hline Telephone & Audio & $\begin{array}{l}\text { Incoming, } \\
\text { outgoing. }\end{array}$ & $\begin{array}{l}\text { Outsiders } \Leftrightarrow \text { Family, } \\
\text { Between family } \\
\text { members }\end{array}$ \\
\hline $\begin{array}{l}\text { Telephone } \\
\text { information } \\
\text { service }\end{array}$ & Audio & Incoming. & Outsiders $\rightarrow$ Family \\
\hline Radio & Audio & Incoming. & Broadcasters $\rightarrow$ Family \\
\hline VCR/tapes & Video, & Incoming. & Industry $\rightarrow$ Family \\
\hline Camcorder & Audio & Within the home. & Between family members \\
\hline $\begin{array}{l}\text { CD-ROM, } \\
\text { CD-I }\end{array}$ & All & $\begin{array}{l}\text { Incoming, } \\
\text { outgoing. } \\
\text { Within the home. }\end{array}$ & $\begin{array}{l}\text { Outsiders } \Leftrightarrow \text { Family } \\
\text { Between family members }\end{array}$ \\
\hline $\begin{array}{l}\text { Music } C D, \\
\text { Laser disc }\end{array}$ & $\begin{array}{l}\text { Audio, } \\
\text { Video }\end{array}$ & Incoming. & Industry $\rightarrow$ Family \\
\hline $\begin{array}{l}\text { Office } \\
\text { documents }\end{array}$ & All & $\begin{array}{l}\text { Incoming, } \\
\text { outgoing. }\end{array}$ & Outsiders $\Leftrightarrow$ Tele-workers \\
\hline $\begin{array}{l}\text { Answering } \\
\text { machine/ } \\
\text { voice mail }\end{array}$ & Audio & $\begin{array}{l}\text { Incoming, } \\
\text { outgoing. } \\
\text { Within the home. }\end{array}$ & $\begin{array}{l}\text { Outsider } \Leftrightarrow \text { Family } \\
\text { Between family members }\end{array}$ \\
\hline Facsimile & Text & $\begin{array}{l}\text { Incoming, } \\
\text { outgoing. }\end{array}$ & $\begin{array}{l}\text { Outsiders } \Leftrightarrow \text { Family } \\
\text { Between family members }\end{array}$ \\
\hline $\begin{array}{l}\text { Internet: } \\
\text { ftp, WWW, } \\
\text { Email. }\end{array}$ & All & $\begin{array}{l}\text { Incoming, } \\
\text { outgoing. }\end{array}$ & Outsiders $\Leftrightarrow$ Family \\
\hline DVD & $\begin{array}{l}\text { Video, } \\
\text { Audio, } \\
\text { Text }\end{array}$ & Incoming. & Industry $\rightarrow$ Family \\
\hline $\begin{array}{l}\text { Home } \\
\text { information } \\
\text { systems }\end{array}$ & All & $\begin{array}{l}\text { Incoming, } \\
\text { outgoing. } \\
\text { Within the home. }\end{array}$ & $\begin{array}{l}\text { Outsiders } \Leftrightarrow \text { Family, } \\
\text { Between family members }\end{array}$ \\
\hline $\begin{array}{l}\text { Digital TV, } \\
\text { interactive } \\
\text { TV }\end{array}$ & $\begin{array}{l}\text { Video, } \\
\text { Audio, } \\
\text { Text }\end{array}$ & $\begin{array}{l}\text { Incoming, } \\
\text { outgoing. }\end{array}$ & Broadcasters $\Leftrightarrow$ Family \\
\hline
\end{tabular}


Between devices and human beings: The information flow is initiated by the commands that people give the devices by means of key-stroke, mouseclick or using a remote control. The devices are computers, televisions and other consumer electronics. Multiple forms of information, such as text, picture, sound etc., are displayed on various media, for instance television screen, computer display, printing paper, or speaker.

Between individuals/non-device mediated: Interpersonal communication has two forms: verbal and non-verbal, or body language. Verbal information combines with body language to form the exact meaning of the information it conveys. Other examples of non-device mediated information exchanges within the home are notices on family "notice boards", house keeping information, hand-written letters, and printed material mediating information sharing between family.

Device-mediated communication: Households with multiple dwelling places, or their members in different locations, have experience of remote interaction via telephone, fax, voice mail and answering machine, email, or computer-generated letters, with other members of the family. Even when all the family members are in the same house, they also may use a tape recorder and player to leave and listen to messages.

These categories and all the interactions in Table 1 summarise the diversity of us of information in the home. To achieve a useful systems to store and process this information requires a number of devices that interact and give the users a useful interface and usable system. However, there are a number of problems associated with the storage of the information itself that are the subject of this paper. The interface and usability of the system are the subject of another paper [1]. The next section looks at the status of home information systems and what the user can expect in terms of their function and facilities in the near future.

\section{CURRENT STORAGE SOLUTIONS}

Storage of information in the home takes many forms, at present. Many of these are paper-based, some are analogue electronic and some are digital. There are diverse devices for storage which are general incompatible and there are varying physical storage requirements (Table 2). 
This diversity has always caused problems for the home and its occupants. The physical storage of paper is problematic. The possession of a quantity of books is considered as healthy amongst most peoples but the storage space required also requires expenditure that is above the cost of the books. In addition to books many households now store music, film, TV programmes, newspapers, magazines and photographs. These all require different storage mechanisms with there attendant additional costs. These costs can be minimal in the case of those who only keep limited information or quite large for those who store most of the information that arrives at the home. The scale can vary from minimal space of one or two metres of shelf space to there being considerable size of shelf space devoted to information storage in the home. All these scenarios need to be incorporated in any design of a home information system and most designs will need to be adaptable to further expansion on use.

Table 2. Storage of information in the home

\begin{tabular}{llll}
\hline Type & Medium & $\begin{array}{l}\text { Storage } \\
\text { Device }\end{array}$ & Analogue/Digital \\
\hline Newspaper & Paper & Box & \\
Books & Paper & Bookshelf & \\
Leaflets/Brochures & Paper & Box & \\
Letter & Paper & Filing system & \\
Telephone message & Tape & Cassette/Solid state & Analogue/Digital \\
Photographs & Paper & Album & Analogue \\
Audio (Cassette) & Tape & Cassette & Digital \\
Audio (CD) & Disc & Case & Analogue \\
Video (TV) & Tape & Cassette & Analogue/Digital \\
Video (Camcorder) & Tape & Cassette & \\
\hline
\end{tabular}

The further complication for home users at present is the trend in consumer electronics that sees new devices and new formats being presented to the public on an annual (or more frequent) basis. For example, audio (music) information has been available on a number of different formats over the last twenty years (see Table 3). All these formats require different devices for use with some (as indicated) only being available for playback.

This diversity is a consequence of market-driven economics and technological development. However, the incorporation of audio in a home information system should be a simple matter of digital storage. Whether this simplicity will remain is yet to be seen. The economic forces for technical diversity are strong and the threat to business of stable technology is a real one. 
Table 3. Audio formats

\begin{tabular}{ll}
\hline Format & Mode \\
\hline Vinyl disc & Playback \\
Cassette & Playback and record \\
Reel-to-reel tape & Playback and record \\
Mini-disc & Playback and record \\
CD & Playback \\
DAT & Playback and record \\
MP3 & Playback, record and distribute \\
\hline
\end{tabular}

\section{HOME INFORMATION SYSTEMS}

Information systems are not common in homes. A personal computer(PC) that has either been derived from a business PC or a games machine is usually all that is considered by users when purchasing equipment for home use. A home information system(HIS), which is an integrated computing system for the home will allow users to store, process and access information in a convenient manner without the diversity of storage that is apparent in home systems at present. This problem was outlined in the previous section on current storage solutions.

The HIS allows all information used in the home to be stored digitally. This includes all paper-based sources which can be scanned or downloaded directly from an Internet source, pictures which are now taken digitally or scanned from previous paper-based sources, audio which is now mainly digital and video which is increasingly becoming digital. The problems of storage and diversity, to a large extent, disappear to be replaced by problems of organisation of resources and usability.

The organisation of the digital resources requires both knowledge and systematic use of computing facilities. For example, simple storage of digital information can be achieved by utilising the file systems available in all PCs. This does not necessarily, however, give an easy form for use of the information. Even with logical file naming and strict directory structures a full archive would be very difficult to use.

As an example consider an electronic photo album with a few thousand photographic images. This would require a few megabytes of storage and be a set of linked directories based on one sort criteria such as film date or location. Finding a particular image would require the user to know its directory and file location or the other information that would locate it in the archive.

A database would provide some of these search facilities but would require more skill and training in use and still not necessarily provide all the facilities required by the user. With a diverse set of information sources the 
problem also becomes one of linkage between the various resources and storage in multimedia databases which are still undergoing research.

The diversity of information formats of the pre-HIS devices is also possible with a HIS in the coding and format of data rather than the packaging and format of the physical device. This can lead to problems and incompatibility between data formats and software used to store and replay items. The problem is mainly one of standards and the standards process[4] and is likely to be solved (partially) by de facto standards for the information types of interest.

A HIS will need to incorporate a number of search facilities for users to be able to replace paper and other systems used in the home. At the same time the systems will allow users to do many things that are currently difficult or only found on expensive equipment, such as programming a evening's television in advance or replaying stored video and audio at specified times along with stored or web-based supplementary information

One other problem for users is the possible large scale of legacy information which could be in many different formats. Paper based sources will need scanning and some may need OCR and video and audio sources will need digitisation into the standard format. All this requires time and effort which may ultimately determine the initial take-up of HIS in the market.

\section{HOME NETWORKS}

The final piece in the HIS jigsaw is the home network. Much effort has been put into looking at the possible automation of home-based devices and some information appliances [2]. This has not resulted in many marketable products and even less installed base of such products. Largely this sort of automation network in not very attractive to households. It is possibly the cost of installation for minimal reward or the fact that the installation is difficult in all but new houses that may be the limiting factors involved.

On the other hand, a home information network has limited extra hardware to the PCs and other information appliances that it links that it is relatively unobtrusive unless the house has a fairly large number of devices, which is rare.

The home network will allow massive storage of data, in all digital formats, that will in turn allow the playback and review of information in appropriate ways to the home users.

One application of home networks is the linkage of web based information to broadcast programmes. Many TV programmes now use web pages to enhance and extend the information disseminated during and after 
broadcast. The use of web pages on a TV during the watching of a broadcast is disruptive in a family environment. A better alternative would be to use small networked PCs to link to the web so that individuals could view the web pages when required. The PCs could be used in the same room as the TV and the information could be cached on the home network on instruction. A typical example would be recipes from a cooking programme or images of original source material for a history programme.

\section{CONCLUSIONS}

The use information systems in the home is an area that will see some growth in the near future. The current diversity of sources and formats of information is likely to increase making it more difficult for the user to make an easy decision to purchase equipment. The move to an information systems approach to home information will solve this problem of diversity but replace it with a problem of use and configuration. This will help some users and hinder others with traditionalists bemoaning the loss of "classic" forms of information such as books or tapes. It is likely that a HIS approach will not be universal with many users preferring a traditional approach to home information storage. However, the change in format for original material from paper and analogue forms to a set of fully digital information service will speed up the move to digital for new users in their first independent homes.

It is, therefore, likely that the growth in HIS will be determined by legacy information and the place of traditional forms in the home, along with consumer electronic marketing and device design being crucial factors. Widespread take-up is possible but the inertia inherent in home systems is still a powerful factor against change.

\section{REFERENCES}

[1] Harris A., Huang W., and Sloane A.(2000) "Home information systems: Design and configuratiion", submitted to the International Journal of Human Computer Studies.

[2] Rusnak J (1997) Anywhere in the home. in IEEE COMMUNICATIONS SOCIETY, 1997 Fourth International Workshop on Community Networking proceedings, Sept. 11-12, 1997, Atlanta, GA, USA. New York, (USA): IEEE Communications Society Press, pp. 19-24.

[3] Sloane A. (2000a) "Internet broadcasting infrastructures for home-based users", in Beardon, Munari and Bloch Rasmussen, (Eds.). "Computers and Networks in the Age of Globalization", Kluwer Academic Publishers, Boston, MA. 
[4] Sloane A (2000b) "The standards process: Tools and methods for standards tracking and implementation" Computer Standards and Interfaces, Vol22, March 2000.

[5] UK government. (1999) - Announcement of move to digital TV. See report by NERA/Smith at http://www.radio.gov.uk/document/misc/digittv/neral.htm accessed 29/1/2000. 